Session F1C

\title{
USING GROUPWARE FOR INTERNATIONAL COLLABORATIVE LEARNING
}

\author{
Tony Clear ${ }^{1}$, Mats Daniels ${ }^{2}$
}

\begin{abstract}
This paper reports the lessons learned from a two year collaborative learning trial between students at Auckland University of Technology (AUT) and Uppsala University. The trials took place using a combination of email and a custom developed Lotus Notes ${ }^{T M}$ database. The first trial involved a case study in which students performed different roles in designing a software solution for an Auckland based nailcare distributor. The second trial built upon the knowledge base of the earlier trial, and required students to evaluate and rank the previous design proposals. $A$ theoretical model developed from the group support systems literature guided some of the changes in the second trial. The software, the collaboration process and the evaluation methods volved over the course of these trials. The challenges of creating global student communities within a short collaboration window in existing courses of study are discussed. Further extensions to this research are proposed and some general recommendations are made.
\end{abstract}

Index Terms - Adaptive structuration theory, collaborative learning, facilitation, group support systems, virtual teams.

\section{INTRODUCTION}

While the Internet has provided a global communications infrastructure, and widespread use of email has supported new modes of rapid and regular communication, email as a technology has several limitations. It is the authors' contention that in spirit email is essentially a private (one-toone) communications medium, although email does have the potential to be used for selected group, and more public forms of communication. The trials reported here have attempted to explore the issues that arise in the use of GroupWare, a technology explicitly designed to support the work of groups. Also known as Group Support Systems (GSS), [1] they have been defined as:

"GSS: any system which supports a group interaction by becoming an integral part of that interaction" [2]

These trials have been motivated by a desire to use Information Technology as a vehicle to teach about the technology itself, and further, to harness the "transformative power of IT" [3], to enable the pedagogy in turn to be transformed.

\section{DESCRIPTION OF THE TRIALS}

\section{First Trial}

The first trial has been reported in [4]. In the course of conducting a Tele-project between two different classes of students in each country, it blended problem-based learning drawn from a live business case, with role-play and international group collaboration. The common task required students to develop a design proposal and feasibility study for a computer game, to assist pharmacy assistants to acquire knowledge about a range of nail care products. The business students at AUT were studying a senior course in Human Computer Interaction (HCI) and the Uppsala University computer science students were studying an introductory course in IT. Since the class sizes differed across the two institutions, AUT students in teams of two were matched with two to three teams of four Uppsala students to make up each overall group. AUT students were intended to act the role of business analysts representing the client's interests, while the Uppsala students were to play the part of software developers.

The trial took place over a three-week period with an intervening two-week holiday break. In the course of the trial students used a collaborative database custom developed in Lotus Notes Domino ${ }^{\mathrm{TM}}$. Numerous usability issues with the system were encountered in the course of the exercise. The process of struggling with an unfamiliar product, a far from ideal user interface and a system that was made available for alpha trial at best, and evolving in the course of the trial, graphically demonstrated to the $\mathrm{HCl}$ students the importance of good interface design. The mixed groups and the open ended and generic nature of the application, caused considerable confusion. Once a naming standard for group entries was developed and partially adopted, some coherence evolved from this initial confusion.

Mixed levels of participation evolved, and varying degrees of electronic interaction took place between the Auckland and Swedish groups. By the end of the exercise the Swedish students had produced several design concepts, displaying considerable imagination and creativity. They had used the collaborative database features in very different ways, although several had preferred to use email alone, bypassing the database completely. The brevity of the trial curtailed opportunities for the groups to continue to develop

\footnotetext{
'Tony Clear, Auckland University of Technology, Computing - Systems \& Technology, Private Bag 92006, Auckland, New Zealand, Tony.Clear@aut.ac

${ }^{2}$ Mats Daniels, Department of Computer Systems, Uppsala University, Box 325, 751 05, Uppsala, Sweden, Matsd@docs.uu.se 0-7803-6424-4/00/\$10.00 C 2000 IEEE 
and critique this work, nonetheless a tangible outcome of the collaboration had eventuated, being a set of draft design proposals to address part of the original purpose. Except for the external email contributions, these proposals were now available in a shared repository for review by other groups, critique or further use.

\section{Second trial}

Given the mixed outcomes of the first trial, and based upon student feedback, observations and reflection by the authors, the second trial took the different approach of assigning a ranking task to the participants. The collaborative database was substantially redesigned, to simplify aspects of the interface, and more specifically support the goals of this second trial. The common task was more tightly defined, less ambitious in scope, and was designed to encourage greater interaction between the student groups. Again the trial involved a Tele-project, but this time built upon the work already done in the previous collaboration.

The goal was for each group (two AUT students, combined with two or more Uppsala groups of four) to individually critique and score, then rank an assigned set of three design proposals. These proposals had been stored within the previous collaborative database and thus were available for this critique.

Once the individual ranking had been achieved, the combined group were to appoint a group leader who would produce a final ranking reflecting a consensus of the overall group opinion. This phase of the trial was intended to generate dialogue between members of the group, and demonstrate the issues associated with gaining agreement within teams across time, space and cultural boundaries.

The trial took place over a four-week period and required students in addition to conducting the assigned task, to report progress on-line individually each week and conduct a final online evaluation of the trial at the conclusion of the exercise. Some of the steps in this trial are given in Table 1.

The trial proceeded more effectively this time, with active contributions from most participants, and six of the nine groups concluding with a joint ranking, reflecting differing degrees of consensus. Again some work between groups had occurred off-line via email, but many groups did use the public discussion area of the database to moderate effect.

There are a number of subtle ethical issues in projects of this nature. The work of oral face-to-face class groups is ephemeral unless recorded in writing. The work of electronic asynchronous groups generates a permanent record of contributors' work, which is stored in the database. Since this was an exploratory learning activity in which students were both co-learners and research "subjects", this project conformed to the AUT definition of a "research project" and thus required formal ethical and project approval. The ethical dimension had been addressed less formally in the course of teaching in the first trial, where students had been asked for consent to re-use their entries, which work formed the basis for the second trial.

TABLE 1

SCHEDULE FOR THE SECOND TRIAL

\begin{tabular}{|l|l|l|}
\hline Session Date & Time (NZST) & Task \\
\hline $\begin{array}{l}\text { Monday } \\
\text { 20/09/99 }\end{array}$ & $6: 00-7: 00 \mathrm{pm}$ & $\begin{array}{l}\text { Register and form groups, research } \\
\text { allocated groups design proposals }\end{array}$ \\
\hline $\begin{array}{l}\text { Wednesday } \\
22 / 09 / 99\end{array}$ & $6: 40-7: 00 \mathrm{pm}$ & $\begin{array}{l}\text { Review merits of design proposals } \\
\text { Report week1 progress (individually) }\end{array}$ \\
\hline $\begin{array}{l}\text { Monday } \\
27 / 09 / 99\end{array}$ & $\begin{array}{l}\text { Individually score the three design } \\
\text { proposals }\end{array}$ \\
\hline $\begin{array}{l}\text { Wednesday } \\
29 / 09 / 99\end{array}$ & $6: 45-7: 00 \mathrm{pm}$ & $\begin{array}{l}\text { Individually rank the proposals } \\
\text { Report week2 progress (individually) }\end{array}$ \\
\hline $\begin{array}{l}\text { Monday } \\
11 / 10 / 99\end{array}$ & $6: 45-7: 00 \mathrm{pm}$ & $\begin{array}{l}\text { Achieve final group consensus on } \\
\text { rankings }\end{array}$ \\
\hline $\begin{array}{l}\text { Wednesday } \\
\text { 14/10/99 }\end{array}$ & $6: 30-7: 00 \mathrm{pm}$ & $\begin{array}{l}\text { Conclude and enter final group } \\
\text { rankings } \\
\text { Report week4 progress (individually) }\end{array}$ \\
\hline
\end{tabular}

\section{A MOdEL FOR FACILITATING COLLABORATIVE TELE-PROJECTS}

The process of conducting collaborative Tele-projects seems to involve a hugely complex interplay of variables. Combined into an educational setting, they certainly defy simple classification. The limitations of experimental and hypothesis testing research based upon natural science methods make choice of research method a challenge. Action research is now actively used in practice settings to give researchers access to the process of educational change and different techniques for its evaluation [7], [8]. The research reviewed here has occurred within an action research framework, which involves cycles of action and reflection. In the course of this reflective process, and in an attempt to better understand the dimensions of this form of learning, the Group Support Systems literature has been perused in search of suitable frameworks. An extension of Adaptive Structuration (AST) Theory [5], [6] has been adopted as a useful explanatory framework to enable some of the key elements of the facilitator's or (in this case) teacher's role to be identified. It is hoped that by applying this Extended AST (EAST) framework, the elements that must be given focus, how they interact, and what interventions are likely to be most effective may be explored. 


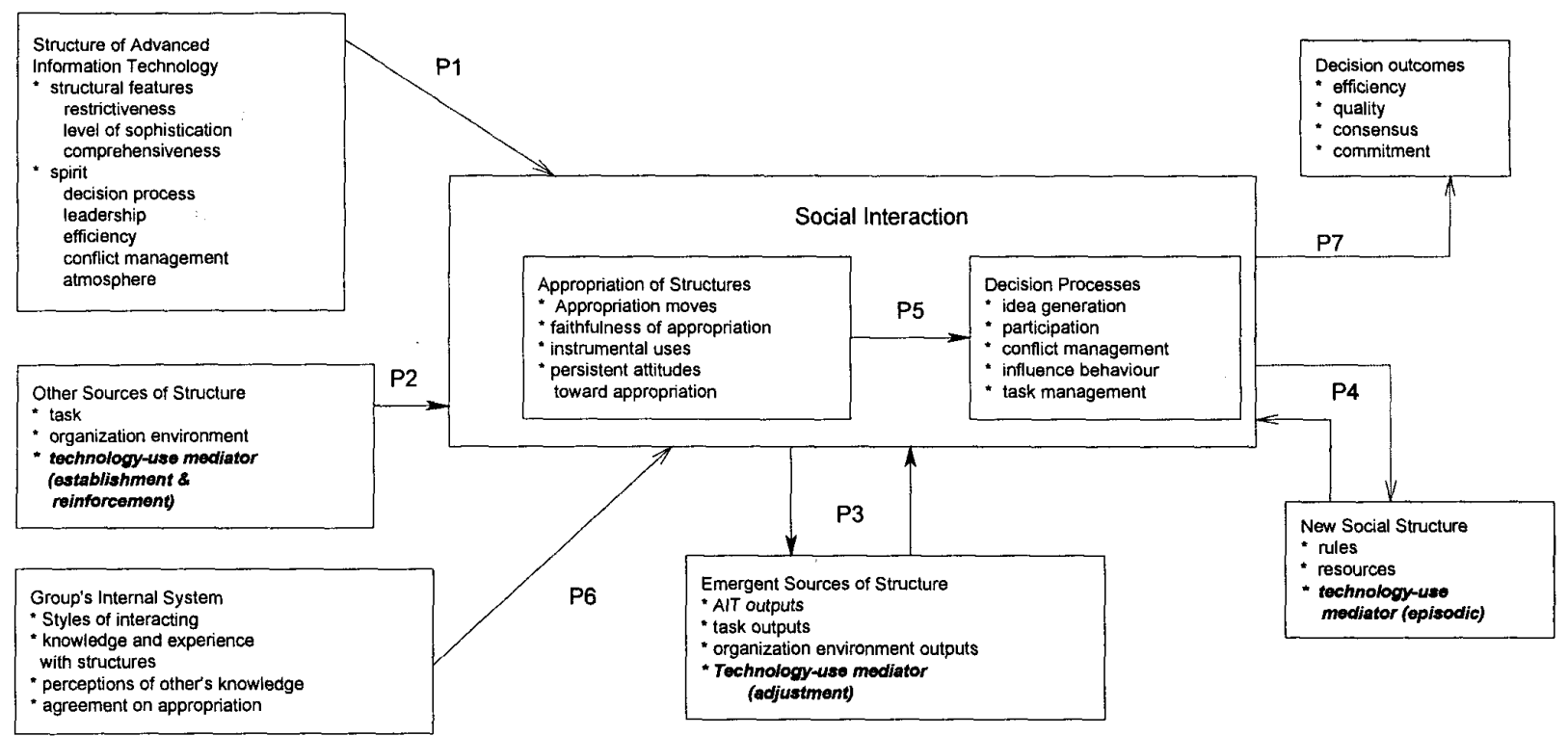

P1. AIT's (Advanced Information Technologies) provide social structures that can be described in terms of their features and spirit. To the extent that AIT's vary in their spirit and structural feature sets, different forms of social interaction are encouraged by the technology.

P2. Use of AIT structures may vary depending on the task, the environment, and other contingencies that offer alternative sources of social structures. P3. New sources of structure emerge as the technology, task and environmental structures are applied during the course of social interaction.

P4. New social structures emerge in group interaction as the rules and resources of an AIT are appropriated in a given context and then reproduced in group interaction over time.

P5. Group decision processes will vary depending on the nature of AIT appropriations.

P6. The nature of AIT appropriations will vary depending on the group's internal system.

P7. Given AIT and other sources of social structure, $n_{1} \ldots n_{k}$, and ideal appropriation processes, and decision processes that fit the task at hand, then desired outcomes of AIT use will result.

\section{FIGURE 1}

SUMmary OF MAJOR CONSTRUCTS AND PROPOSITIONS OF EXTENDED AST (EAST) MODEL. [5], [6]

As can be seen, this framework suggests a complex set of interactions which shape the use of $A I T^{\prime}$ 's, or in this case more specifically the use of GroupWare to support the collaborative trial. The extension to $A S T$ in the model above lies in the introduction of the role played by the technology use mediator [9], in this case the teacher as facilitator of the collaborative trial. This role is suggested to operate as:

1) an Other Source of Structure at the establishment of a trial, or to reinforce the modes of use that are desired by the participants;

2) an Emergent Source Of Structure during the trial itself, while the AIT is in use,

3) a means of bringing about a New Social Structure through episodic change

By using the above framework, we can conceive of a collaborative Tele-project via a classic input-process-output model, which is dynamic and non-deterministic, as is true of any learning situation, no matter our hopes and goals as educators. While the framework may not give us ready answers, it gives us a mechanism by which to study, change and better understand the elements of the process.

\section{SOFTWARE DESIGN AND DEVElopMent}

Lotus Notes Domino ${ }^{\mathrm{TM}}$ is an industrial strength GroupWare product with sophisticated security, multimedia document, file and data handling, full text search and indexing and database replication features. It is client server based, web enabled, and has a fourth generation language development environment, which also supports among other things a scripting language. For these trials the database was developed mainly using the fourth generation features of the product, such as forms, views, action buttons, and navigators. The main database was stored at AUT on our Lotus Notes server, and students accessed the system via the web using standard web browsers.

The application designed to support these trials has evolved from an initial concept, with a number of structured generic elements (project, document, section, discussion thread, response etc.), but considerable freedom for user

October 18 - 21, 2000 Kansas City, MO

$3^{\text {th }}$ ASEE/IEEE Frontiers in Education Conference F1C-20 


\section{Session F1C}

definition of elements. In the first trial the genericity proved a barrier to use. It inhibited communication between groups, navigation of the database and effective learning of how to use the system. In the second trial a much more tailored development approach was taken. While less generic, this approach gave more contextual clues, which eased use of the database, and reduced rates of error. For instance, instead of a field for project name allowing open ended entry, and project/group names such as "club kafka", which meant nothing to the remaining members of the group, the new design enforced entry of group name via a drop down list box. Group naming standards were thus able to be enforced (e.g.. group001NZ001, group001SE001), rather than simply recommended via a standard which was not read or not adhered to, causing confusion all round. In this way the design of the application brought structure to the process. The original application had three main areas,

1) a discussion area, within which documents and sections or structured discussion threads could be accessed;

2) a reference area for attached files and

3) a reference area for websites of interest

These areas were augmented by an online evaluation form enabling students to anonymously enter their reviews of the trial, and a secure set of views by which the researchers could access the on line evaluations.

In the second trial:

1) the discussion area was tidied up to some extent by enforcing naming standards, improving navigation and reducing the depth of hierarchies in the application.

2) Functionality was added to enable individual scoring, individual ranking and group ranking activity to be performed, and the results of this viewed by participants as they evolved.

3) Provision was made for weekly progress reporting via an online logbook, and views were designed for participants to indicate the reported progress of individuals and groups.

4) Again anonymous online evaluation forms were designed and a secure set of views to provided to assist in their analysis.

A number of limitations with the functionality of the application remain to be addressed, and usability remains an issue. Feedback from students requires further analysis to assist in this, but a means of linking the system more readily to the students' standard email mailbox could be useful, (perhaps via Notes agent functionality, which can for instance automatically send mail to specified recipients or groups).

\section{Evaluation}

An EAST evaluation framework considers results in terms of the output variable decision outcomes (as identified in figure 1 above) under the four criteria of efficiency, quality, consensus, and commitment. For these trials the deliverables from the exercise are equivalent to the decision outcomes. Gaps in data collection inhibit a full evaluation, since the model in figure 1 had not been developed at the time of the first trial, but it does provide a base against which the outcomes can be reviewed.

1) efficiency of decision outcomes - trial 1

at overall group level -7 of the 8 groups produced at least one design proposal from their contributing subgroups.

No group completed their joint feasibility studies.

At subgroup level - of 20 Uppsala subgroups, 10 completed a design proposal, 1 of these being for the wrong overall group, 10 failed to complete a proposal, but 2 of these may have done so by email without the final results being forwarded to the authors

efficiency of decision outcomes - trial 2

at overall group level - 6 of the 9 groups (by self-report of the AUT student groups in class) produced a group ranking of the proposals. From the database itself it appeared that there was considerable confusion between subgroup and group levels. Database entries correlated with the self-report data in 2 cases as "confirmed" rankings, in 2 cases as a "draft" entry only, and in 1 case as an "uncategorised" entry. In 2 other cases later entries by subgroups countered the self-report data, and in 2 cases earlier entries by subgroups counteracted the self report data.

2) quality of decision outcomes - trial 1

the quality of design proposals submitted in the trial were generally high, and offered interesting and innovative concepts for software games. Subjectively most would be ranked as good to excellent, with the main issues relating to technical and operational feasibility of the proposed solutions quality of decision outcomes - trial 2

Given the problems of consistency in rankings noted above, this outcome is difficult to judge. Conclusions appear to differ between groups, as do degrees of consensus.

3) consensus about decision outcomes-trial I

Given the lack of feedback between the groups in the time available, it must only be assumed that the subgroup submitting the proposal had at least come to a consensus among its own members

consensus about decision outcomes-trial 2

The group ranking process explicitly provided for an indication of degree of consensus within the group about the ranking finally confirmed. Of those self report groups which had come to a conclusion, it appeared that the degree of consensus was at the level of "strong agreement" or "agreement" (top 2 agreement categories on a 5 point Likert scale). Of the other 


\section{Session F1C}

groups, similar outcomes appeared to be the case but at the subgroup rather than group level.

4) commitment to decision outcomes -trial 1

since the feasibility study element of the task had not been completed, it is speculative to comment on each group's commitment to the proposal developed. However, the Swedish groups had demonstrated a degree of commitment to the exercise by successfully completing their proposals.

commitment to decision outcomes -trial 2

from the consensus responses above, it can be assumed that the groups who had come to terms with the task would abide by their decision. However a counter argument to this would come from the lack of commitment to changing status of entries from "draft" to "confirmed", or "uncategorised" to "confirmed". The subgroups who entered directly contradictory "confirmed" entries also demonstrated either confusion about group membership, or no commitment to the overall group outcomes.

The evaluation could be extended to consider results in terms of the New Social Structure construct (as identified in figure 1 above) under its three categories of rules, resources and technology-use mediator. Further work is necessary to determine how best to evaluate outcomes against these headings. However some general comments may be made. The naming standards referred to above, and the reporting and ranking processes adopted in the course of the trial could be regarded as rules. The practice of weekly online progress reporting was instituted earlier in the course for AUT students, and this seems to have successfully transferred to a regular practice during the trial itself. The Uppsala students by contrast, were not active or regular in their progress reporting. It appears that for AUT students the practice had become an outcome stabilised as rules of acting in future learning situations. This is consistent with the AST model in which "knowledge and experience with structures" leads to "faithfulness of appropriation", "persistent attitudes towards appropriation" and generates therefrom a new set of rules that become part of the social structure. An example of episodic change from a technology-use mediator is given by the redevelopment of the database between the two trials. The process of embedding new structures in the design of the application, or the revision of the common task, or the group establishment process could all constitute such examples.

\section{CONCLUSION AND RECOMMENDATIONS}

In the course of these two trials much has been learned about the intricacies of combining IT with learning, research with teaching and linking student groups beyond the traditional classroom boundaries. It is a challenge to organise unbalanced groups of diverse, geographically distant and busy students. It has been suggested that GroupWare is not a "tool" but a "medium", and "new media have been much more difficult to invent, create and operate than new tools" [11]. In the research situation the software is being developed on-the-fly, suffers usability problems and lacks the full guides that would accompany a mature product. But more positively, prototyping to accommodate emerging users needs can be demonstrated in a live context.

These undergraduate trials have emphasised the "interdependence of research and teaching" [10]. However the overheads of project and ethical approvals, and the tension between voluntary participation of "subjects" and summative assessment of "students", are very real ones, which require careful management.

Some of the differences and developments between trials have been discussed above, and a theoretical framework proposed against which to conduct and evaluate such learning activities. DeSanctis \& Poole [5] suggest analysis using detailed analytic schemes, identifying the degree to which actors faithfully appropriate the technology, (i.e. use it in accord with the spirit of its design in order to achieve their goal). However they also note that "simple schemes may do as well as elaborate schemes. Development and debate about ways to codify the social structure of technology and action would appear to be a healthy agenda for researchers" [5].

From an educational perspective these trials have had mixed success. They are certainly not a trivial task, with technical, time, administrative, assessment and student pressures to be overcome. They impose an overhead on a course, requiring considerable extra effort, negotiating skills and management of technical crises and workload peaks. Nonetheless for the collaborating partners they have been a fascinating, and challenging experience, from which considerable insight has been gained. Experimenting in real time in cyber-space with twenty groups of people has been both intriguing and at times very funny. For students a large amount of their learning has probably gone unrecognised, but their feedback does acknowledge that they have gained in knowledge, understanding or been beset with frustrations in the course of the trials. Certainly the in-class sessions have often shared some very funny moments, as the voices of larger-than-life cyber characters somehow echo over the ether.

While far from a stable or mature product, the present collaborative database has some worthwhile features that can be used successfully. Some of the processes and issues that must be managed in collaborative trials are also better understood. The need for a supportive, reliable and patient collaborating partner is critical, as is the need for some level of institutional support. Establishing a more sustained and adequately funded research project, which links differenttime, different-place students in joint courses, with fully assessed project work using such GroupWare is a desired next step. 


\section{REFERENCES}

[1] Nunamaker, J., Dennis, A., Konsynski, B., "Interaction Of Task and Technology to Support Large Groups", Decision Support Systems, 5, 1989, 139-152

[2] Whitworth, B., "Generating Group Agreement In Cooperative Computer Mediated Groups: Towards An Integrative Model Of Group Interaction", PHD Thesis, 1997, University of Waikato

[3] Leidner, D., Jarvenpaa, S., "The Use of Information Technology to Enhance Management School Education: A Theoretical View", MIS Quarterly September, 1995, pp. 265 -291

[4] Clear, A., "A Collaborative Learning Trial between New Zealand and Sweden - Using Lotus Notes Domino ${ }^{\mathrm{TM}}$ in Teaching the Concepts of Human Computer Interaction", ITiCSE Conference Proceedings, June 27July 1, 1999, pp. $111-114$, Cracow, Poland

[5] DeSanctis, G., MS., Poole., "Capturing The Complexity In Advanced Technology Use: Adaptive Structuration Theory", Organization Science, $5 ; 2,1994$, pp. $121-147$

[6] Clear, A., "International Collaborative Learning - The Facilitation Process ", ED-MEDIA Conference Proceedings - Addendum, Jume 19-24, 1999 , pp. $1759-1764$, Seattle, Washington

[7] Carr, W., \& Kemmis, S., "Becoming Critical: Knowing Through Action Research", 1983, Deakin University, Victoria

[8] Zuber-Skerrit O., (ed.) "New Directions In Action Research", 1996, Falmer Press London

[9] Orlikowski, W., Yates, J., Okamura, K., Fujimoto, M., "Shaping Electronic Communication: The Metastructuring of Technology in the Context of Use", Organization Science, 6;4, 1995, pp. 423 - 444

[10] AIT, "Auckland Institute of Technology Research Report",

1998, AIT, Auckland

[11] Beaudoin -Lafon, M., (Ed.) "Computer Supported Cc-opendtive Work", (1999) Wiley, Paris 